\title{
Momento ao advogado de uma transação internacional
}

Truman Bidwell, advogado militante em Nova York, na área de direito internacional.

Negociar no meio externo ou nas fronteiras da lei internacional constitui naturalmente assunto complexo. Ficamos em presença de jurisdições diferentes e, como foi aqui dito, tratamos com culturas diversas e até, segundo ouvimos, com emoções várias. Todavia, isso não será assim tão diferente do que tratar com homens de negócios numa situação em que cada parte procura, como é habitual, ganhar algo para si. E eu creio que o essencial para fazer negócios no estrangeiro com êxito é entrar numa situação negocial em que se tenha o que é necessário e em que o que cada lado tenha seja o necessário. Tem havido discussões à volta desta mesa durante os últimos dois dias quanto à imposição de termos, acerca de situações em que um país ou uma companhia podem ditar condições. É da minha experiência e bem assim da das pessoas com quem eu trabalho que a imposição de condições redunda em má negociação. Sem querer diminuir a importância do meu professor nem a da profissão de muitos de vós, a verdade é que nenhum advogado jamais conseguiu converter em bom um mau pacto negocial. Conseqüentemente, conquanto o contrato, as suas cláusulas e a anexa documentação sejam assuntos de muita importância, sem dúvida, o que é mais importante de tudo é o pacto negocial em si mesmo. Ele terá de fazer sentido para nós e para todo o mundo que esteja envolvido na transação. Se ele beneficia um só lado, resultará simplesmente em intranqüilidade e o negócio eventualmente cairá por terra. Temos estado falando de exportações, mas eu preferia, nos meus rápidos comentários aqui, não tratar de qualquer transação em especial e antes trazerIhes uma espécie de sumário de muitas das coisas que aqui têm sido ditas. $\mathrm{O}$ que Ihes vou transmitir é uma relação prática das preocupações a observar por um advogado numa transação internacional.

Para começar, o nosso sistema nos Estados Unidos é um tanto diferente do vosso sistema aqui, no sentido de que o advogado e o homem de negócios se olham como parceiros de uma aventura. Pelo que eu entendi por conversas que tive aqui com os meus colegas, é bem mais usual, como o é também na Europa, que o homem de negócios estruture e defina uma transação e depois busque o advogado, ou já tarde no próprio dia ou, quantas vezes
Truman Bidwell

quando a transação já se complicou. Não estou fazendo propaganda de vossa Ordem de Advogados, mas penso realmente que as coisas ficarão mais fáceis, sobretudo numa transação internacional, se meterem o vosso advogado no assunto o mais cedo possível. O papel deste, no início da transação, é assistir o homem de negócios na apreciação dos riscos da transação, dos quais já tanto ouvimos falar, e ajudá-lo a estruturá-la, de modo a que ele se proteja e à sua companhia o melhor possível dentro das circunstâncias e que a mesma transação beneficie o mais possível a companhia brasileira. A forma de transação é importante. Ouvimos discutir hoje muitas delas e existem muitas facetas a considerar na transação, mas é preciso ponderar, ao entrar na aventura, se será melhor usar capital emprestado, debêntures, consórcio ou toda uma outra variedade de formas legais disponíveis. Não se pode ficar preso a qualquer forma ou formato. Quem vai negociar pelo mundo tem de ser imaginativo. As três mais importantes considerações a observar na estruturação de uma transação, a meu ver e em qualquer caso, são essencialmente: ter estruturado a transação com o máximo benefício econômico para o meu cliente; reduzir ao mínimo o seu risco, a sua vulnerabilidade em conseqüência da transação; isso tem a ver com a forma jurídica para o que poderei designar um assessor no país estrangeiro, pois assim procedendo eu limito o risco da minha companhia pátria e posso discutir a segurança com o meu cliente: que segurança será necessária e em que nível isso se relaciona diretamente com a lei do país com o qual estamos pensando em fazer negócio.

Por outro lado, um assunto que transcende a perspectiva corrente mas não é menos importante no risco do negócio, é a estruturação da transação no sentido de minimizar o impacto fiscal sobre o cliente. Poderia organizar-se vários seminários acerca de como minimizar o encargo fiscal nas transações internacionais. Bastará dizer aqui que esse encargo e suas implicações devem constituir um fator da maior importância a considerar.

Finalmente, julgo que o controle cambial, o risco de desvalorização cambiária, etc. são algo que deve merecer, nas transações transnacionais, uma especial atenção do advogado. 
O passo seguinte numa transação, uma vez que se reconheça, em princípio, que o negócio interessa, é a negociação. E aqui eu julgo que esteja a verdadeira essência da arte do advogado. Ajudar o cliente a compreender o ambiente negocial em que ele está penetrando num determinado país é extremamente importante. $\mathrm{O}$ advogado, nessa fase, deve atuar como diplomata, como homem de negócios e como conselheiro, ajudando a aplanar as diferenças entre os clientes. Acredito que, como advogados, nós temos uma capacidade de comunicação uns com os outros naquilo que eu julgo seja uma base não-emocional a bem dos respectivos clientes a quem podemos ajudar por vezes já em águas tempestuosas.

Vamos admitir, por fim, que se decidiu que o negócio tem interesse, que as negociações foram conduzidas com êxito e brilhantismo em benefício do cliente e é hora do advogado se voltar para a essência da sua arte, que é reduzir toda a conjuntura das negociações a um documento escrito. Não me atrevo a,discutir os termos do documento, porque o dr. Freire já o fez brilhantemente. Prefiro equacionar alguns dos cuidados cöm que me preocupo quando estou negociando no estrangeiro, que são afinal em boa parte os mesmos que se me impõem quąndo negocio no meu país.

Em primeiro lugar é muito importante para o advogado conhecer as leis do país para onde vai, ou melhor, para onde o cliente vai. Se eu tiver que representar um cliente, o que espero fazer em breve, que venha fazer negócios no Brasil, a primeira coisa que eu farei é aprender tudo o que puder acerca das vossas leis. É claro que eu já fiz isso para vir aqui falar convosco. E tenho muito material disponível, pelo menos no meu escritório, acerca das leis de muitos países. De passagem, direi para aqueles que o ignoram, que uma firma contábil em Price Waterhouse publicou um livro intitulado Negociando em... e aí pode-se escolher o país que se quiser do mundo, porque a seu respeito existe uma bela exposição com as leis mais relevantes, as práticas principais, etc., em cada país; vale bem o investimento.

A seguir trato de contratar um advogado do país para onde vou, pois não pretendo aconselhar o meu cliente, por mais versado que eu me julgue no assunto, sobre a legislação de um país que não seja o meu. Mesmo nos EUA, muitas vezes confinamos o nosso conselho aos estados em que estamos licenciados. Retornando às especificações do contrato, uma coisa que não foi ainda aqui mencionada hoje, mas que é por certo importante, e lamento ter de dizer que é muitas vezes descuidada, é como, onde e quando eu recebo ou tenho de entregar o que tiver de pagar. Ainda que os que me ouvem possam julgar isso óbvio, falando recentemente com um co- lega meu aqui no Brasil, o qual estava gizando um contrato na recente excitação do campeonato de futebol, tive conhecimento de que, sem que ninguém se apercebesse, foi marcada uma data limite para um domingo, o que criou um problema potencialmente sério sobre se era a de sexta ou a de segunda-feira a desvalorização a ter em conta.

Tem depois, como o dr. Freire referiu, o assunto das representações e garantias. Estas são importantes, porque por meio delas cada parte está dizendo à outra, realmente, o que vai entregar. No meu país e em outros existem duas espécies de garantias e temos de estar atentos a elas. Uma é a garantia expressa, ou seja, aquela que se presta efetivamente no contrato. A outra é uma garantia implícita, isto é, uma garantia que a lei diz que se está dando, quando, por exemplo, se vende um certo produto e quer se esteja ou não prestando. Muitos de vós saberão provavelmente que no meu país temos uma legislação bastante extensa sobre controle de produtos e segundo a qual, basicamente, se se vender um artigo no país e esse artigo prejudicar alguém, o vendedor é responsável perante essa pessoa pelo dano causado. Aqueles de nós que defendemos os acusados costumamos designá-la de "teoria do alçapão". É uma fonte de preocupações e é um dos tais casos em que se deve pedir conselho quando se está importando ou pensando em negociar no país. Nós temos realmente o mesmo conceito daqui, o de que não estamos presentes para o efeito de concluir negócios se tivermos apenas um agente de vendas sem poderes para nos obrigar, mas, não obstante, poderemos cair na alçada da jurisdição dos nossos tribunais desde que tenhamos produtos à venda nos EUA.

Alguns de vós, de mentes jurídicas mais aguçadas e rápidas, estarão já dizendo: "Ah, mas eu posso escrever qualquer coisa no sentido de que me desligo dessas coisas...". Puro engano: as declarações são aqui inteis.

A próxima coisa a considerar é, evidentamente, o financiamento e ouvimos aqui referir fontes disponíveis, como o Eximbank, o World Bank, os bancos comerciais, os bancos da OPEP e os fundos, tendo a estrutura do contrato com estas instituições sido bem-descrita pelo dr. Freire.

Um outro ponto que não foi abordado foi a questão da garantia a exigir que seja remetida. Se estivermos, por exemplo, exportando a prazo, poderemos procurar obter garantias da pessoa para quem se exporta. Isso levanta a questão de saber se existem bens de raiz entre os bens dessa pessoa, se esses bens são valiosos, ou, no caso de querer outra garantia, se essa garantia é válida e, na hipótese de querer uma letra de crédito, se essa letra tem valor. De acordo com a lei do meû país, considerava-se que 
se se tinha obtido uma letra de crédito, era como se fosse pagamento. Soubemos recentemente que nem mesmo as letras de crédito dos bancos são hoje necessariamente cobráveis.

Seguidamente, a questão do seguro. Existe seguro de guerra, seguro de risco político, seguro contra a responsabilidade resultante de produtos controlados, o seguro guarda-chuva que cobre todas as coisas que não se tinha pensado em cobrir e há, é claro, o seguro do crédito. Ouvi dizer de vários colegas que o seguro contra produtos controlados é aqui muito caro. Se o é, mas se se está negociando ou se quer negociar nos EUA, eis uma área que deve ser cuidada, pois, sem isso, estar-se-á mal-aconselhado nos negócios, pelo menos no meu país.

O assunto das representações e garantias ainda exige mais um comentário, segundo creio, ou seja, qual é a finalidade de tudo isso. Basicamente, a finalidade em vista é obter uma confirmação de tudo aquilo que esperançosamente se escutou no decurso das negociações e preparativos do negócio. Com referência à opinião do advogado, esses são documentos sempre difíceis de negociar e sobre os quais os advogados não gostam de opinar e por isso insisto na necessidade de pedir o conselho de um advogado de outro país, que esteja assistindo.

Discutimos os riscos de apropriação e se isso é ou não um assunto pertinente. Não quero evidentemente tecer especiais comentários a tal respeito, bastando dizer que é uma matéria que também tem de ser encarada quando se vai ao Terceiro Mundo ou mesmo em qualquer outro lugar e eu ainda, na sessão de ontem, me referi rapidamente a um tratado entre os EUA e a China, há pouco assinado, no qual o risco de apropriação foi de certo modo acau telado por acordo entre os dois governos no sentido de que se houvesse um ato de expropriação o expropriado poderia vender efetivamente a sua propriedade para o governo, que ficaria sub-rogado nas suas pretensões. Discutimos largamente a força maior e as cláusulas penais e a necessidade de as definir com todo o cuidado. E eu acho que é muito importante não só delinear cuidadosamente essas condições, como também o alcance e as conseqüências do que acontecer. Na realidade, as cláusulas penais não são muito comuns nos contratos entre particulares. Também se falou de imunidade de soberania, que é um assunto a ser, sem dúvida, considerado quando nós, representando uma companhia privada estamos negociando com uma instituição governamental ou quase governamental. Riscos do câmbio estrangeiro e a quem incumba suportá-los, é outro assunto que não pode ser descurado. Discutimos também o problema da jurisdição e eu referi que, pelo menos no meu país, se se estiver vendendo para ele, correse o risco de ficar sujeito à jurisdição dos tribunais americanos de acordo com o que na nossa lei é conhecido por "estatutos de longo prazo". Julgo que a definição fala por si. Constato que a arbitragem não é muito comum aqui no seio da vossa comunidade jurídica, mas é algo que vem sendo mais e mais usado por quem faz negócios, pelo menos nos EUA. Também tem a virtude de neutralizar a, por vezes, bem-árdua decisão de qual a lei aplicável. Também há que levar em consideração as leis de usura locais e tanto nós quanto os clientes não podemos do mesmo alhear dos aspectos contábeis e demais exigências da jurisdição local. Se estivermos tratando de transferência de tecnologia, há que examinar as patentes, a sua validade e a eficácia das marcas que estamos pensando em negociar. É necessário, como assinalou mr. Dealy, examinar os requisitos regulamentares do país estrangeiro e do mesmo modo a sua atmosfera regimental. Isso inclui, é claro, as restrições às companhias estrangeiras que possuem bens no ativo; não existem muitas no nosso país, mas algumas existem, sobretudo, relacionadas com a aviação. Um rápido apontamento aconselha ainda que, se se vai negociar, tem que se detectar a natureza e o caráter das estruturas comerciais locais ao nosso alcance, as formalidades requeridas eventualmente, se há pedido de residência a fazer, qual a estrutura do capital, a designação social, se pode utilizar nos EUA a sua, a forma de administração, livros e registros requeridos, restrições sobre dividendos, em que extensão se pode dispor ou não uma concessão de posse, se pode usar acordos de participação de modo a que as partes possam acordar nas conseqüências das transações e porventura da sua rescisão. E em seguida vem, é claro, todo o problema da alfândega, das tarifas e encargos que são obrigatórios.

Também tem-se de levar em consideração, quando se vai negociar num país, as leis trabalhistas locais e as conseqüências que elas podem ter sobre o pessoal a ser contratado no país, pois ao admitir um empregado pode ser extremamente difícil depois desfazer o vínculo empregatício. Também ouvimos falar muito em subsídios governamentais. Não vou acrescentar nada a tal respeito, mas quero fazer notar que quando se vai fazer negócios de país para país devem-se examinar os acordos comerciais existentes entre eles. Por fim, se se for a um dado país como credor para arrumar uma transação devem-se examinar os direitos dos credores nesse país para ter certeza sobre a nossa proteção.

Como foi indicado antes, as conseqüências das falhas e os remédios ao alcance também precisam ser examinados. Em tais casos, as cláusulas sobre danos estipuladas devem ser consideradas. Também é de considerar, se se estiver negociando com um crédito fraco, como pode acontecer, as conse- 
qüências da falência perante a jurisdição local. Outro fator também importante é como vai terminar a relação jurídica estabelecida. Quero fechar apenas com um pensamento para vós. O dr. El Khosheri sugeriu que os negócios deveriam ser separados da política e eu acredito e estou de acordo com ele. Eu fico pensando como negociantes e advogados podem construir uma ponte entre o Brasil e os EUA e entre todos nós e o resto do mundo, com o que se providenciará uma base de entendimento que suple- mentará aquele que os nossos governos estão tentando construir. Por último quero contar-lhes uma experiência que tive recentemente numa conferência relativa à China. Tivemos dois dias de arrastadas discussões legais durante as quais alguém perguntou a um dos participantes chineses qual era o segredo do êxito comercial conseguido pela China. Ele respondeu e eu cito: "Paciência, confiança e amizade". Eu acho que se adotarmos estas qualidades, teremos êxito.

\section{Arrendamento mercantil}

Luiz Alberto Americano, procurador da Procuradoria Geral da Fazenda Nacional.

Gostaria de falar algumas palavras sobre um tipo de contrato que está entrando muito em moda entre nós - o de leasing - , para o qual existe um termo bem nosso chamado arrendamento mercantil. $\mathrm{O}$ arrendamento mercantil ou leasing está assumindo entre nós certa importância e tende a se tornar cada vez mais importante. A bibliografia brasileira sobre a matéria, mais recente, é muito precária e há alguns poucos trabalhos, mas realmente nós estamos carecendo de um trabalho mais profundo sobre o assunto que vem revestido de novas características. $\mathrm{O}$ arrendamento mercantil pode englobar, com este nome ou com o nome de leasing, ou seja, suponhamos: eu sou uma companhia de aviação e quero aumentar a minha frota. Então, eu arrendo um avião sob determinadas condições de uso, através do contrato de leasing. É uma operação que o leasing abrange. Mas o leasing abrange também uma outra operação que é, vamos dizer assim, um financiamento garantido, disfarçado com as roupas do leasing. Eisto ocorre, vamos supor, eu que sou o proprietário da aeronave e preciso de dinheiro para o meu giro de negócios. Então vendo o avião para uma
Luiz Alberto Americano

instituição financeira e esta instituição me aluga o avião. Aí então nós vemos que o leasing pode também abranger esta operação de financiamento garantido.

Insisto em falar na garantia porque, através dessa segunda modalidade de leasing nós podemos quebrar, em detrimento dos credores do devedor a regra de igualdade de preferência nos créditos. Um deles terá um crédito de maneira real. Isso é importante quando nós pensamos nos contratos internacionais de leasing; uma companhia que assim proceder e tiver outros contratos de leasing poderá, indiretamente, estar quebrando a regra pari passu, de preferência nos créditos.

E há um terceiro aspecto do leasing que eu gostaria de mencionar, porque eu gostaria de ouvir do colega Truman Bidwell, que pode nos colocar a par das úteis informações, porque nós só estamos vendo o leasing como maneira de importar, mas nós podemos utilizar o leasing como maneira de exportar.

\section{Arrendamento mercantil}

Truman Bidwell, advogado militante em Nova York, na área de direito internacional.

É verdade que em meu país, têm-se duas formas diferentes de leasing, este é um tópico acerca do qual os advogados americanos levam dias em
Truman Bidwell

reuniões tentando aprender uns com os outros, pois se trata de uma área terrivelmente complexa e esotérica. Sem tentar instruí-los numa coisa que pou- 